\title{
HOW CONFUCIUS INFLUENCES CONSUMER'S VIEW ON SOCIALLY RESPONSIBLE CORPORATIONS
}

\author{
Felix Tang, Hang Seng Management College, China \\ Vane-ing Tian, The Open University of Hong Kong, China \\ Alan Ching-biu Tse, The Chinese University of Hong Kong, China \\ Eric Chee, Hang Seng Management College, China
}

\begin{abstract}
This research discusses and extends a Confucius-based concept, junzi and its five virtues to explain how Asian consumers may evaluate the actions of a company from five dimensions (i.e., humaneness, righteousness, propriety, wisdom, and integrity). It develops a consumer-oriented measurement of junzi orientation in evaluating the actions of corporations. The result of a face-to-face survey conducted in Hong Kong $(n=1,114)$ indicates consumer's assessment of a corporation's junzi orientation significant affects how they evaluate the corporate image of a corporation operating in a Chinese society. Our finding extends Miao's (2004) insight on decision making into the consumer domain; that is, the junzi concept provides a culturally-rooted framework in Asian consumer's purchase decision making process. Our finding also echoes Tian's (2010) concern of whether the five virtues are equally important in the eyes of consumers. Our results suggest that among the five dimensions, humaneness (ren), propriety ( $(i)$, and integrity (xin) are relatively more important in improving a company's image. Our results on age group differences should also be insightful to marketers in developing segmentation, positioning, and CSR strategies in Asian markets.
\end{abstract}

References available upon request 